\title{
Conclusion: Co-creating Inclusive Digital Futures
}

This book has attended to the ambivalences and challenges associated with demographic ageing and the increasing digitalisation of social life and public services. One of its key arguments is that the co-creation of digital public information services needs be understood in relation to the wider public sector information infrastructures. The requirements and scope of co-creation processes go beyond approaches such as co-production, co-design or civic open data use. Co-creation of digital public services demands a different set of engagement methods than traditional co-production approaches, because co-production so far only marginally considers digital service design. The co-design of digital public services, however, comes with its own challenges - in particular when engaging older and/or non-tech savvy citizens. Co-creation also goes beyond approaches to co-design, because such approaches are mostly limited to the design of intra-organisational information systems or stand-alone applications. Co-created digital public services however, need to be sustainably provided and maintained for all citizens. Hence, a broader range of issues needs to be considered than for many of the research-led co-design projects that promote co-creation. Co-creation also goes beyond the civic use of open data, because it is based on a collaborative relationship between service and data providers on the hand and a broad range of citizens on the other. In addition, working with (open) data is just one of several streams of activity in co-creation.

Based on three co-creation projects conducted as part of the Mobile Age project, this book demonstrated that co-creation is a multi-stakeholder process, which involves activities beyond the ones typically associated with co-production, codesign or civic open data approaches. Figure 1 provides a summary of the streams of activity including corresponding pre-conditions and co-creation results. Ideally, the co-creation process and results contribute to the overall strategy and policies of the local communities, governments and service providers involved. Existing collaborations in between and across government units and social care service providers come to be amended and new collaborations emerge as a result of the co-creation process. Existing services are the basis for new digital services and hence the result- 


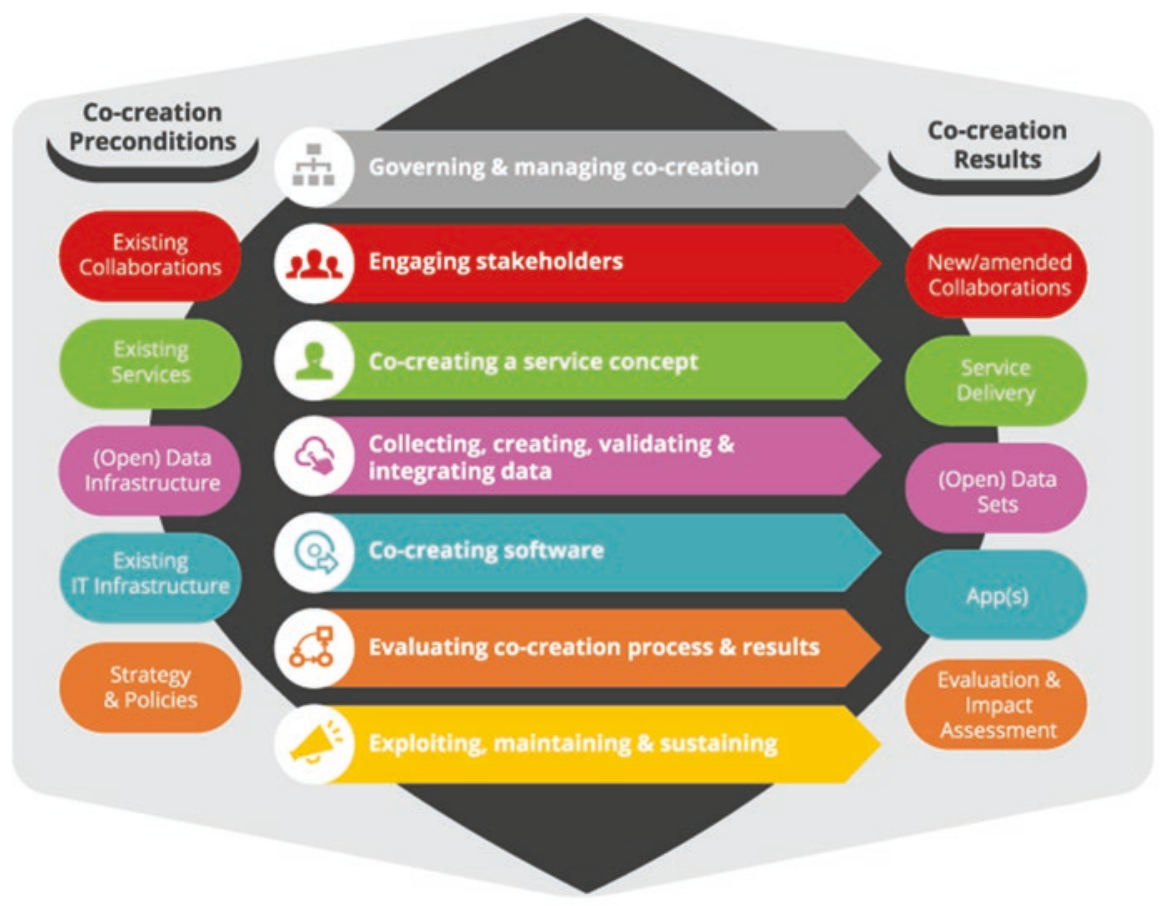

Fig. 1 Framing conditions and resulting change of co-creation projects

ing service will become embedded in the existing service portfolios of government and social care service providers. Only then can a service be sustainably maintained. Likewise, the existing data infrastructures will include new or amended/validated data sets that represent the needs and requirements of the service users (e.g. through new/amended data structures and attributes).

In addition to this general assessment on the different types of pre-conditions, activities and results, the book examined specific challenges of co-creating digital public services with older adults. These related to:

1. the sharing of control over decisions concerning the definition of a problem to be solved and the design of its solution;

2. the sharing of knowledge and expertise;

3. the enabling of individual and social change.

Chapter "Learning from Co-creation Practice" has already provided learning points for each of these aspects in relation to the engagement of older adults. In the following, I conclude with some more general observations.

The first and positive conclusion-relating to the governing of co-creation and the sharing of control-is that co-creation is indeed an appropriate method to develop digital public information services that meet the needs of older users and achieve an output that is better than existing, comparable services. In Bremen, we developed digital mobile services in two co-creation projects which are now running 
on the city information portal and which are maintained by local partners. ${ }^{1}$ In Zaragoza, the collaborative maps are integrated into the existing city information service infrastructure. From the experience of these three co-creation projects, there is no one best way to set up and govern a co-creation process. Rather, we identified three framing conditions or fitting challenges: a representational fit, a target fit and a problem fit, which are depicted in Fig. 2 and discussed below.

Representational Fit The co-creation projects described in this book differed with respect to their definition of the intended targeted audiences. Two different approaches can be observed in the two cities:

- Open recruitment: In Bremen the participants of the co-creation processes were-to some extent-self-selecting. They either heard about the projects from local social care service providers (e.g. via leaflets), through newspaper articles or through acquaintances. They then decided themselves whether this project was of interest to them and they were qualified to contribute.

- Targeted recruitment: In Zaragoza, the collaborating senior citizen centres preselected six to eight senior residents per district based on a number of characteristics defined by the two departments of the city council that facilitated the process. These characteristics included those differences within the target group of older adults, which the core project group considered most relevant (e.g. mobility/immobility, digital literacy skills, gender).

There are hence differences with respect to whether co-creators are considered as advisors to a co-creation process (its problem definition and final solution) or as representatives of a target audience, a distinction that is prominent in co-design approaches. As Arnstein (1969) pointed out, there needs to be some kind of legitimation of co-creators to assume the role of representatives in civic participation projects. This accountability is less rigid in participatory design projects in which

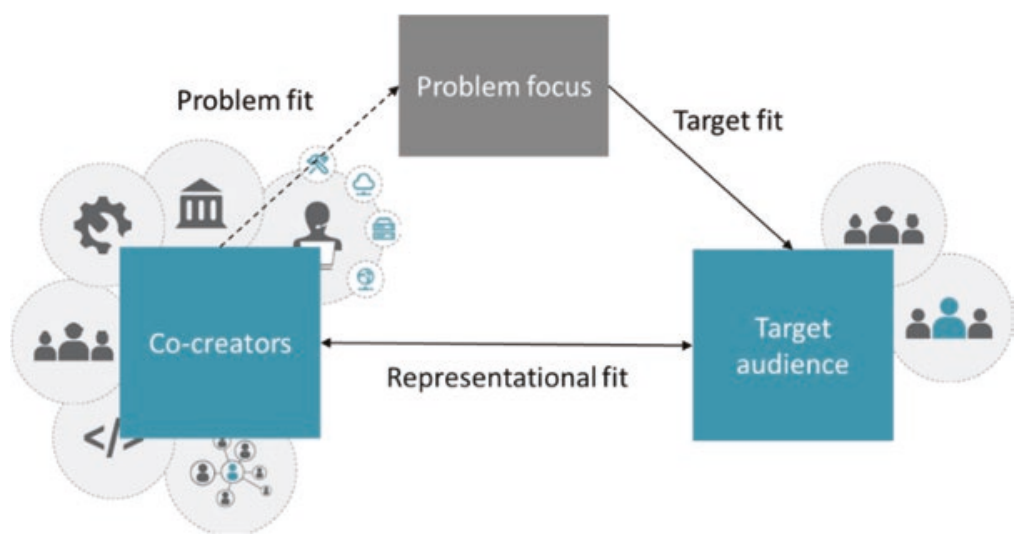

Fig. 2 Framing conditions of co-creation projects (adapted from Jarke \& Kubicek, 2019)

${ }^{1}$ (1) www.bremen.de/osterholz/senioren (2) www.bremen.de/hemelingen/senioren. 
users are generally understood as either advisors or representatives. For co-creation, this poses a challenge with respect to representing (and taking into account) the life worlds and media use practices of a broad variety of citizens.

Target Fit In Zaragoza, the target audience of the service was defined by the city administration through specific characteristics. The individuals participating in the co-creation process were hence always also representing certain, well-defined parts of the senior population. In contrast, in Bremen, the participants themselves defined what characteristics made a difference with respect to "doing age" in their neighbourhoods. Based on these characteristics we co-created personas and scenarios. The target audience of the co-creation process in Bremen became hence refined as part of the co-creation process and through continuous engagement with participating older adults and intermediaries. These were two, distinct ways of constructing the ageing population as target audience of a co-created service.

Problem Fit The refinement of the target audience had implications for the problem definition and the subsequent development of a service idea. Overall, these approaches made a difference to how future users of a digital service came to be scripted. For example, in the case of Bremen, the primary target audience came to be defined as those older adults living in the district who are still relatively mobile and independent.

In all projects, citizens only became involved to a limited degree in the delivery of the co-created services. However, in Zaragoza in order for the service to run, citizens need to report incidents and suggest improvements. They also need to participate in the participatory budgeting process. The role of service providers (and intermediaries) depends very much on the type of problem area but most importantly on the role local government assumes. The more the anticipated service falls into the area of responsibility of social care service providers, the more responsibility they will assume during a co-creation process. Figure 3 provides an approximation to the scope of action of government (as facilitators or digital information service providers), social care service providers and older adults. There is a delta with respect to the role government plays during the second phase (find the right problem) and third phase (find the right solution) as it is doubtful that government will only assume a consultative role in a co-creation project, if they are facilitating the process. The scope of action for each co-creator group is determined by different factors. One the one hand, government's scope of action is determined by the overall public information infrastructure, including existing collaborations, policies and strategies, existing IT and (open) data structures, procurement laws, interoperability requirements, budget constraints and legal and organisational restrictions. Similarly, social care service providers' scope of action is determined by the alignment of a problem area to their existing service portfolio, their policies and strategies, their funding schemes and embedding in existing ICT-infrastructures. On the other hand, the scope of action of older participants is determined by their life worlds, digital media use practices as well as their ability and willingness to participate. 


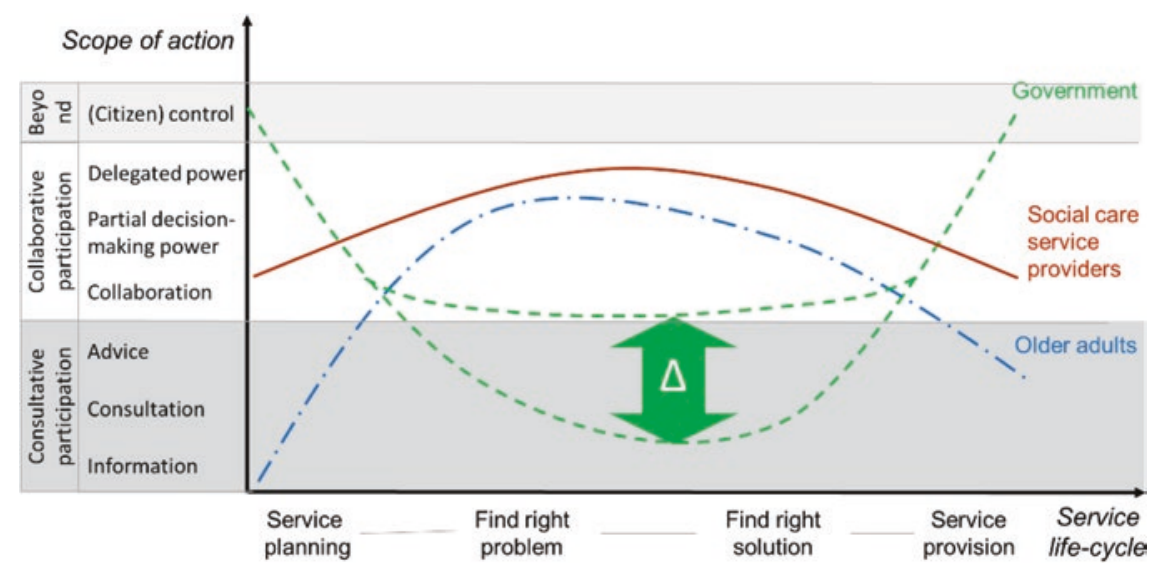

Fig. 3 Scope of action in co-creation projects

Hence, co-creation is indeed an appropriate method to develop digital public information services. However, there exists - throughout a co-creation process-a tension between on the one hand, a need for standards and alignment to existing public information infrastructures in order to ensure continuity and sustainability, and on the other hand, customised and flexible uses of information services which are based on the very local and situated life worlds of older participants.

The second conclusion-relating to the sharing of expertise and knowledge-is that the co-creation of digital services works well with older adults, including those with little or no digital literacy skills. However, the performance and achievements of co-creation processes seem highly contingent and dependent on several factors. Even though, older adults are important civic actors contributing to their local communities and families as well as to society as a whole, they are-so far-rarely included as (design) partners when it comes to public socio-technical innovations. If, however, technical innovations are designed without them, old age is mainly understood as a problem that needs a technological fix. What our three co-creation projects demonstrated is that co-creation can challenge this assumption: In cocreation older adults' expertise and lived experience become resources for the cocreation of societal value, knowledge and technology. Indeed, when older adults are involved in the process of identifying, conceptualising and designing digital public services, these services become more relevant and meaningful for all ages.

In order to do so, a co-creation process needs to provide meaningful and suitable interventions: In co-creation, older adults need to be enabled to explore their life worlds and reflect on them (perspective making). They also need to be enabled to share this with others (perspective taking). In the projects described, we used probes as well as ideation walks for perspective making between older adults and perspective taking between participants and co-creation facilitators (e.g. government). Both types of interventions produced a range of boundary objects, which allowed cocreators from different communities of practice to communicate and collaborate; 
they allowed to manage the tensions between diverging, differently situated viewpoints (Bowker \& Star, 2000).

The outcome of each of the exploration phases were problem definitions in form of scenarios based in the life worlds of the participants. These were aligned with the public information infrastructures through standardised forms such as data tables in Bremen Osterholz or questionnaires and documentation sheets for the walks in Bremen Hemelingen and Zaragoza. Such interventions, hence, allowed for the development of shared classification schemes and subsequent co-creation of sustainable solutions. Figure 4 provides an overview about how different types of boundary objects allowed for perspective making and perspective taking across different communities of practice. For example, probes and walks worked well in combination with data tables and walking templates as they enabled diverse groups of actors (service providers, older citizens, and software developers) to communicate effectively and engage in co-creation.

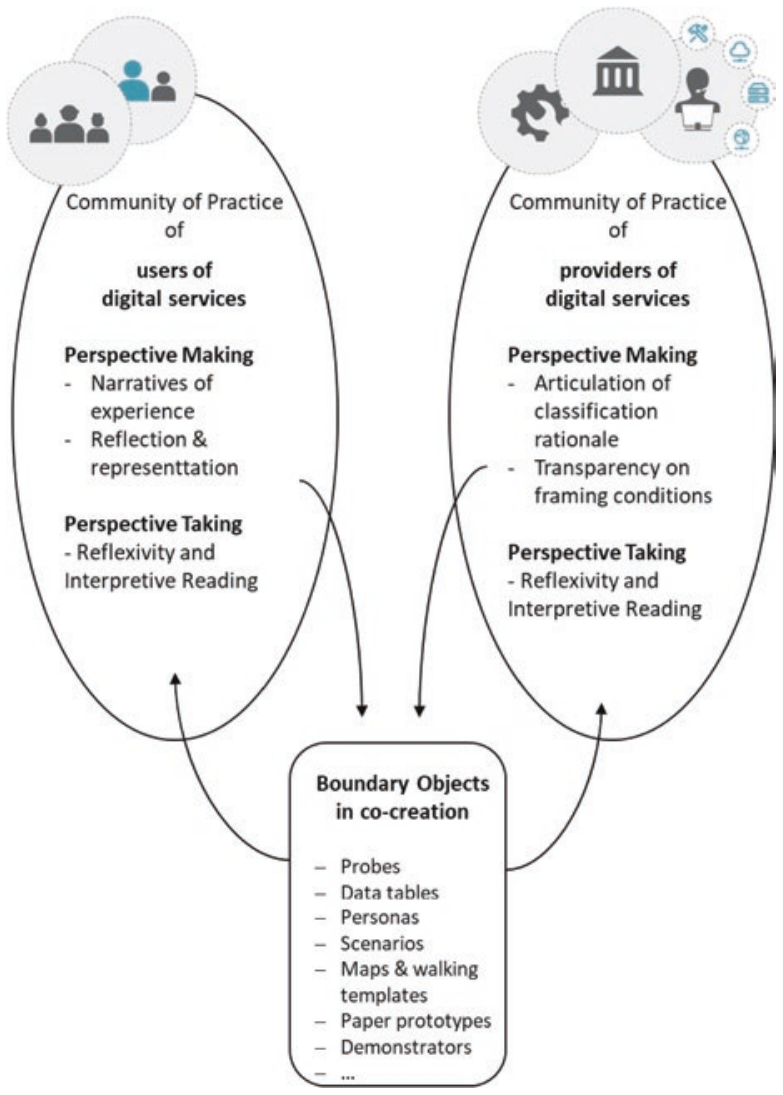

Fig. 4 Boundary objects facilitated the perspective making and perspective taking across communities of service providers and service users 
Hence, the co-creation of digital services works well with older adults, including those with little or no digital literacy skills. It requires a combination of methods from co-design to co-production approaches that can balance the tensions between situated knowledges and use practices versus standardised public service infrastructures.

The third conclusion - relating to enabling change - is that not every digital public service is equally suited for co-creation. Technology design and the development of new technologies have-throughout human history-been envisaged as ways of responding effectively to societal challenges, problems and obstacles. In particular, information and communication technologies are amongst those that are viewed to have changed social order and sociality profoundly (e.g. Castells, 2000; Latour, 1990, 2007). They are also situated in a discourse of innovation and progress, a discourse that the public sector cannot avoid.

With regard to the readiness of government and public administration, and their legal and technical discretion as well as the relevance of the knowledge and possible contributions of citizens as co-creators, local information services should be given first priority. In particular, Mobile Government offers many opportunities where either printed information or static websites can be improved by apps for mobile devices and meet the promise of anytime-anywhere-access to required information. Figure 5 depicts the suitability of different types of public services for co-creation. Based on our experience, we identified local information services as most suitable as they require a high degree of speficity to local contexts and hence allow a greater scope of action for the participating co-creators.

A lasting social as well as individual change can only be implemented if the resulting service does indeed respond to the problem definition. A positive impact of a digital service on social problems depends on the extent-and more importantly-the ways in which citizens come to use a service. We have learned that co-

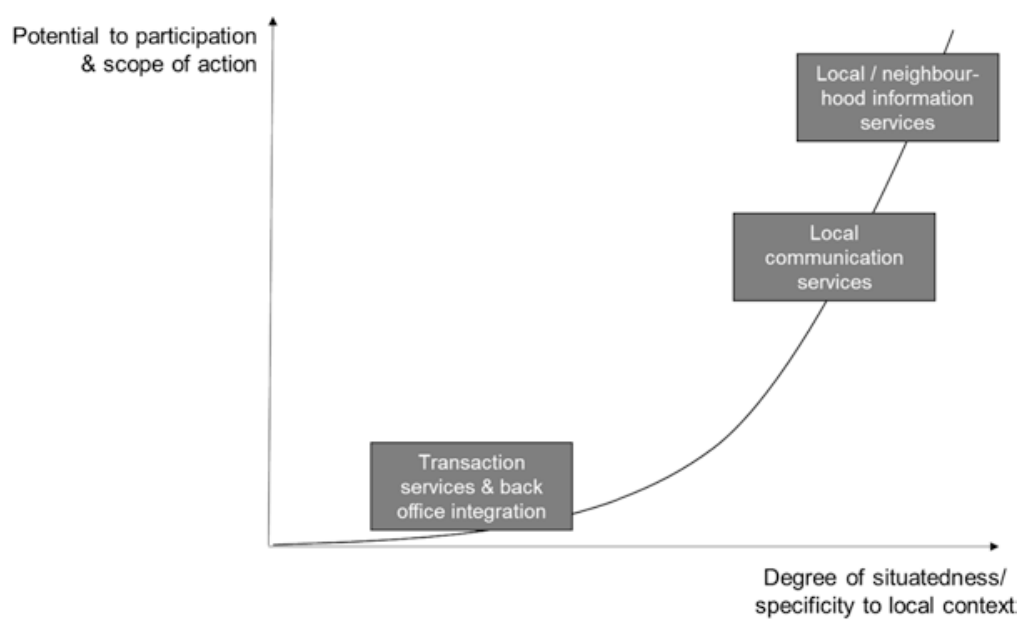

Fig. 5 Suitability of services for co-creation 
creating a service makes this service more appealing for the target group of older adults.

However, there is a challenge concerning the access and usage of a service. So far, older adults are less likely to use digital public services than younger generations. In our co-creation projects, we drew two different consequences: 1) we supported the access to the provided information through the provision of additional printed materials and 2) we supported the access and usage of the digital service through tablet courses during the co-creation projects and-to the extent possibleafter their termination. Hence, a multi-channel approach (e.g. providing information online and in print) is necessary for a transitional period. Such printed material may raise interest in the digital counterpart. If appropriate support structures are in place, the co-created services may motivate older adults to take part in courses imparting digital literacy skills.

In sum, there are six challenges to co-creation that we identified across the three co-creation projects (see Fig. 6). There is a target fit with respect to the definition of a co-creation's target audience in relation to its problem focus. As a co-creation project progresses, the target audience becomes more and more refined and may lead to the exclusion of those citizens who are not represented in the co-creation process. This is based in a representational fit: Do those people who participate in a co-creation project represent the target audience adequately? Depending on the representational fit of co-creators, this may lead to a problem shift, which means that the specific concerns of those included in the process, overlay the needs of a wider population. A fourth challenge is a resource fit and relates to the abilities of those

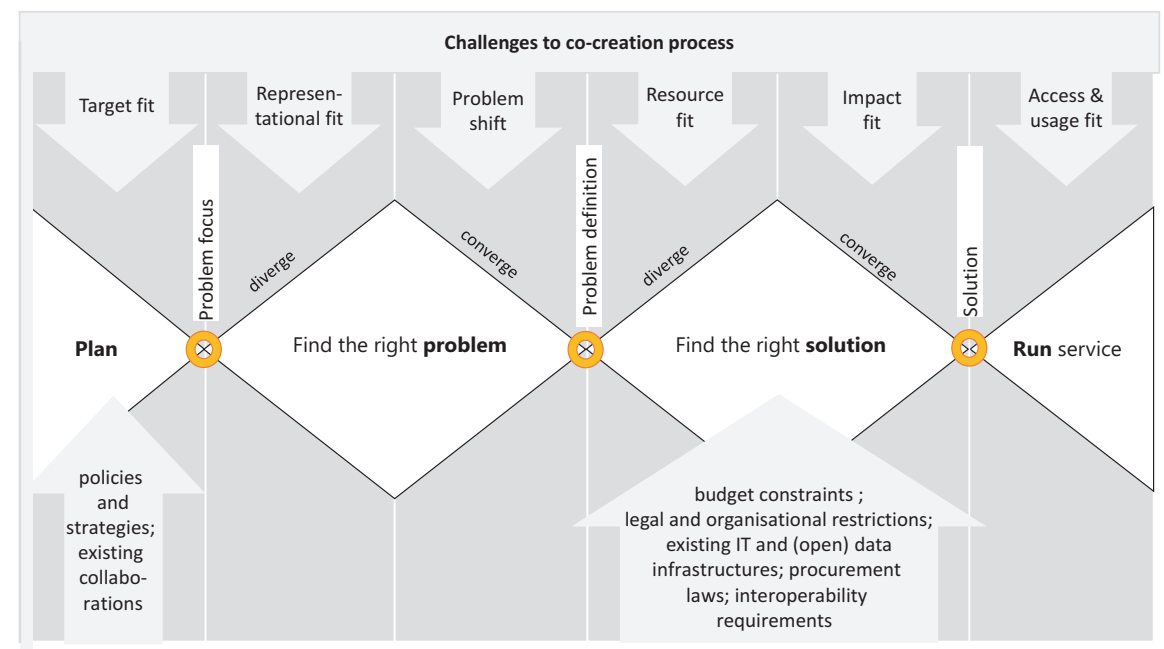

Fig. 6 Challenges to co-creation process 
older adults participating. A co-creation process requires an adaptable and continuous recruitment strategy in order to allow for the engagement of additional cocreators whenever skills or specific knowledge are required that go beyond (the capabilities of) the core participants. A fifth challenge is an impact fit and relates to the match between the original problem focus and the co-created solution. A final challenge relates to an access and usage fit: A lasting social change and impact may only be achieved, if the take-up of the resulting service by its target audience is actually accomplished. All of these challenges are framed by the public information infrastructures as part of which the digital public services is being co-created.

To conclude, co-creation may become a way to improve the lack of user-centricity and user experience of digital public information services. However, there is no guarantee for its success. It is a complex multi-task and multi-stakeholder process, more demanding than traditional citizen participation. Due to the openness and complexity inherent to any co-creation process, providing strict guidelines and recommendations is not possible. However, the learning points identified in this book provide evidence on ways to co-create better, more user-centric public services with and for older adults: If co-creation is based on a continuous engagement and participation of (older) citizens then a more inclusive digital future is possible.

Open Access This chapter is licensed under the terms of the Creative Commons Attribution 4.0 International License (http://creativecommons.org/licenses/by/4.0/), which permits use, sharing, adaptation, distribution and reproduction in any medium or format, as long as you give appropriate credit to the original author(s) and the source, provide a link to the Creative Commons license and indicate if changes were made.

The images or other third party material in this chapter are included in the chapter's Creative Commons license, unless indicated otherwise in a credit line to the material. If material is not included in the chapter's Creative Commons license and your intended use is not permitted by statutory regulation or exceeds the permitted use, you will need to obtain permission directly from the copyright holder.

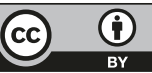

